\title{
Deep Convective Plumes in the Ocean
}

\author{
By Terri Paluszkiewicz, Roland W. Garwood \\ and Donald W. Denbo
}

$\mathrm{D}$ EEP CONVECTION is a process in which the mesoscale ocean circulation and atmospheric forcing work together to weaken the ambient stratification and to cause surface waters to sink to great depths with large vertical velocities. This process plays an important role in bottom and intermediate water formation and ultimately in the large-scale thermohaline circulation, which in turn plays a central part in determining global climate. Until now, our understanding of deep convection was based on observations and models of the mesoscale effects of deep convection. With recent advances in numerical modeling techniques and instrumentation, we have begun to study the role of the mixing elements: the deep, penetrative convective plumes shown in Figure 1. These plumes are turbulent, have a large vertical scale and have attributes that are unique for turbulent plumes: they are affected by the nonlinear relationship between temperature and pressure in the density of sea water and by rotation. Numerical model results, such as those shown here, clearly demonstrate that turbulent mixing affects climate-related processes; that is, deep convective plumes are evidence that small-scale features affect the large-scale circulation.

Two types of convection have been linked with deep water formation: near-boundary sinking and deep penetrative sinking in the open ocean (Solomon, 1974; Carmack, 1990). The proper representation of these processes in numerical models becomes important in simulating the thermohaline circulation. In coarse resolution models, openocean deep convection is not resolved, and research is underway to understand the process and to develop a parameterization of this process for ocean circulation models. The near-boundary sinking is also of interest, but here we focus on some

T. Paluszkiewicz. D.W. Denbo, Pacific Northwest Laboratory, Battelle/Marine Sciences Laboratory, 1529 W. Sequim Bay Rd., Sequim, WA 98382, USA. R.W. Garwood. Naval Postgraduate School, Monterey, CA 93940, USA. recent advances in the study of deep open-ocean convective plumes.

Deep convection occurs primarily in the Greenland, Labrador, Weddell, and Mediterranean Seas, and the water masses formed in these locations contribute to the deep circulation. Estimates of the amount of deep water formed by open-ocean deep convection range from $5 \times 10^{6}$ to $10 \times 10^{6} \mathrm{~m}^{3}$ $\mathrm{s}^{-1}$; this is of the same order of magnitude as the estimates of deep water produced near ocean boundaries $\left(7 \times 10^{6}\right.$ to $\left.10 \times 10^{6} \mathrm{~m}^{3} \mathrm{~s}^{-1}\right)$ (Sankey, 1973; Killworth, 1979, 1983; Carmack, 1990). During the preconditioning phase of deep convection, a background of low static stability is created. This is followed by a mixing phase that occurs where preconditioning has been active and is characterized by intense and rapid cooling, evaporation and/or freezing. Surface waters then become denser than deeper waters; as a consequence, parcels of water descend with entrainment and vigorous mixing at vertical velocities of $2-10 \mathrm{~cm}$ $\mathrm{s}^{-1}$. In the sinking and spreading phase, the newly formed dense water equilibrates with the surroundings and spreads horizontally.

Deep convective plumes (Fig. 1) transport and mix water over many hundreds of meters during a time period of hours to days (Aagaard and Carmack, 1989). Where deep convection occurs, the across-isopycnal advection produces intermediate and bottom water and controls the vertical structure of deep water masses. Ultimately, these water masses influence the deep circulation patterns that in turn affect the meridional heat transport within the ocean. Manabe and Stouffer's (1993) climate simulations have shown that the thermal and dynamical structure of the oceans could change in response to model climates with increased $\mathrm{CO}_{2}$. In their simulations, the addition of low-salinity surface water at high latitudes prevents the ventilation of the deep ocean, thus reducing, or in some cases nearly extinguishing, the thermohaline circulation. The dynamics of the oceanic uptake of $\mathrm{CO}_{2}$ and tracers is therefore strongly determined by the rate of downward transport of surface waters to depth.
This process plays an important role in bottom and intermediate water formation and ultimately in the large-scale thermohaline circulation . . . 

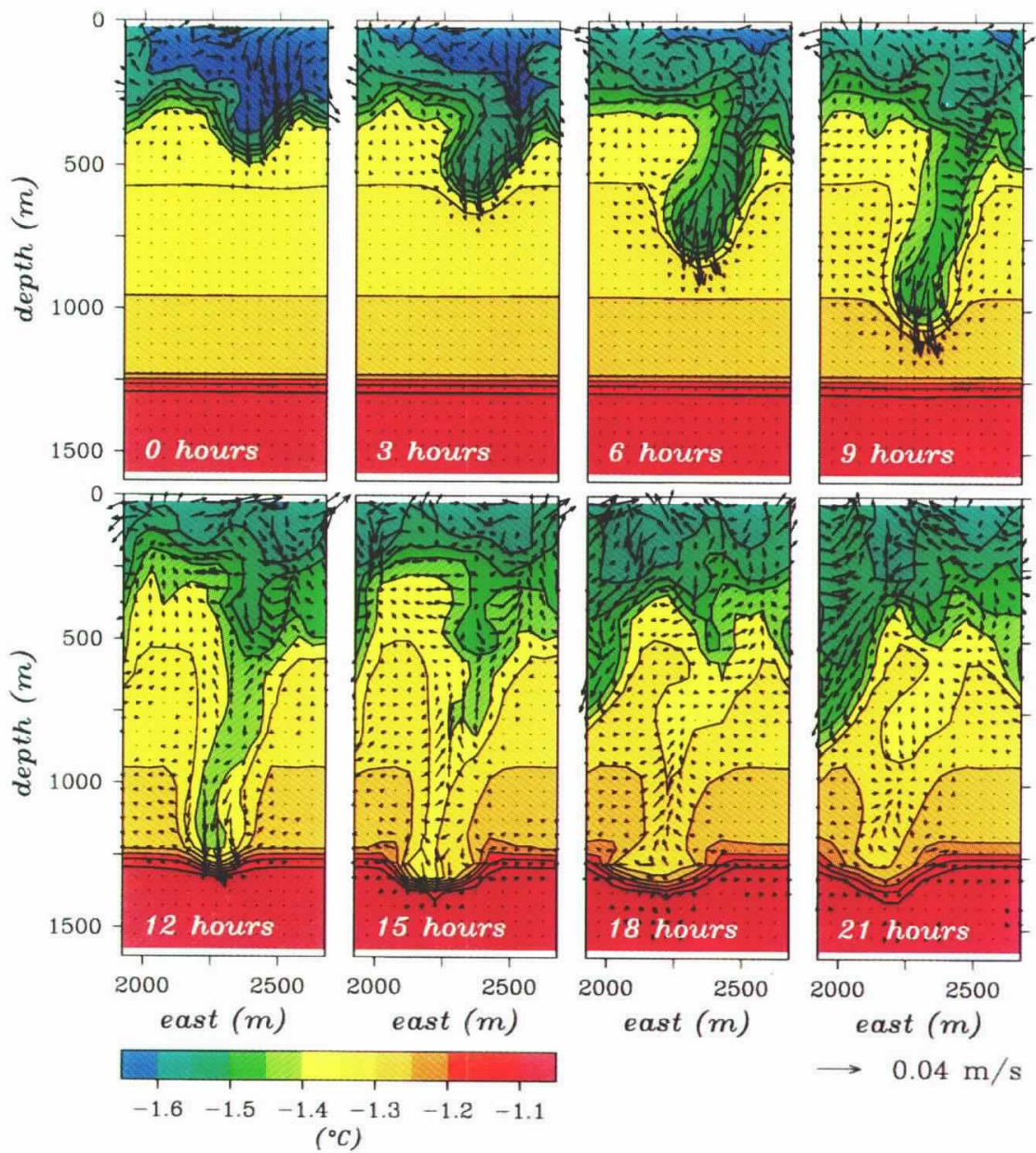

Fig. 1: The simulated potential temperature evolution from an LES experiment of open-ocean deep convective plume formation (Courtesy D. Denbo).

\section{Observations of Deep Convective Plumes}

There are several scales of organization that are believed to be important in deep convection in which plumes represent the smallest-scale process. Gascard (1991) notes that on the mesoscale, chimneys and eddies play an important role in the water mass formation process.

Plumes are convectively driven vertical motions. Whereas shallow convection, or mixed-layer deepening, has scales of hundreds of meters (Killworth, 1983; Guest and Davidson, 1991), deep convective plumes have vertical scales of 1 to 2 km (Gascard and Clarke, 1983), horizontal scales on the order of $1 \mathrm{~km}$ and associated vertical velocities of 2-10 $\mathrm{cm} \mathrm{s}^{-1}$ (Rudels et al., 1989; Schott and Leaman, 1991; Carsey and Garwood, 1993; Jones and Marshall, 1993; Roach et al., 1993; Schott et al., 1993a; Denbo and Skyllingstad, 1994; Garwood et al., 1994). Time scales associated with convective plumes are reported to be several hours to several days (Rudels et al., 1989; Roach et al., 1993). The convective plumes appear as isolated regions of vertically coherent, downward vertical velocity when measured by acoustic doppler current profilers (ADCPs).
Active convective elements with horizontal scales of $<1 \mathrm{~km}$ have been observed in the Greenland Sea (Schott et al., 1993a) and Mediterranean Sea (Schott et al., 1993b; The THETIS Group, 1994). Surface evidence of convective plumes was found in synthetic aperture radar (SAR) imagery by Carsey and Garwood (1993) (Fig. 2a). The SAR imagery was able to distinguish plumes because they appeared to be ice covered and the convective return areas were open water. The sizes of the plumes (200-400 $\mathrm{m}$ in diameter) agreed with model experiments and with the scaling arguments of Jones and Marshall (1993). The surface expression of plumes and the association with ice indicate that the brine from ice growth might act as a trigger of convection. The compensating upwelling flow and consequent heat flux may retard ice growth. Scott and Killworth (1991) found evidence of vertical plumes that were not the result of surface instabilities. These vertically well-mixed areas may have been $3 \mathrm{~km}$ wide and extended downward from the base of the mixed layer (Fig. 3a.). These observations indicate that there may be two different modes of instability, parcel instabilities and layer instabilities.

\section{Theories and Hypotheses for Deep Convective Plumes}

Gravity-driven oceanic convection is both nonlinear and nonhydrostatic, with three-dimensional interactions among turbulent eddies resulting in a cascade of turbulent kinetic energy (TKE) from the largest plume scale to the microscale. The following two processes, normally negligible in turbulent boundary-layer dynamics, become important in the deep convective plumes: (i) thermobaricity, a consequence of the nonlinear relationship between temperature and pressure in the density of sea water and (ii) the Coriolis force.

Gill (1973) first showed that sinking cold and saline Weddell Sea shelf water formed by freezing conditions would experience additional downward acceleration with increased pressure as the dense water flowed down the sloping bottom. McDougall (1984) called this nonlinear effect in the equation of state thermobaricity. Thermobaricity influences deep convection significantly when sea water is colder than $0^{\circ} \mathrm{C}$. In an analysis of the TKE budget, thermobaricity has been shown to enhance the buoyant production of mixed-layer turbulence, resulting in a probable increase in entrainment and a possible mid-depth maximum in TKE for the deepest turbulent mixing layers in the polar seas (Garwood, 1991). The use of the full nonlinear equation of state for sea water is necessary in order to retain the thermobaric effect on the energetics of deep convection (McDougall, 1987; Aagaard and Carmack, 1989; Denbo and Skyllingstad, 1992; Garwood et al., 1994; Paluszkiewicz and Romea, 1994). 
ERS-1 SAR BLOWUP

FROM: $3016-213373.6^{\circ} \mathrm{N}, 11.1^{\circ} \mathrm{W}$ FEBRUARY 12, 1992

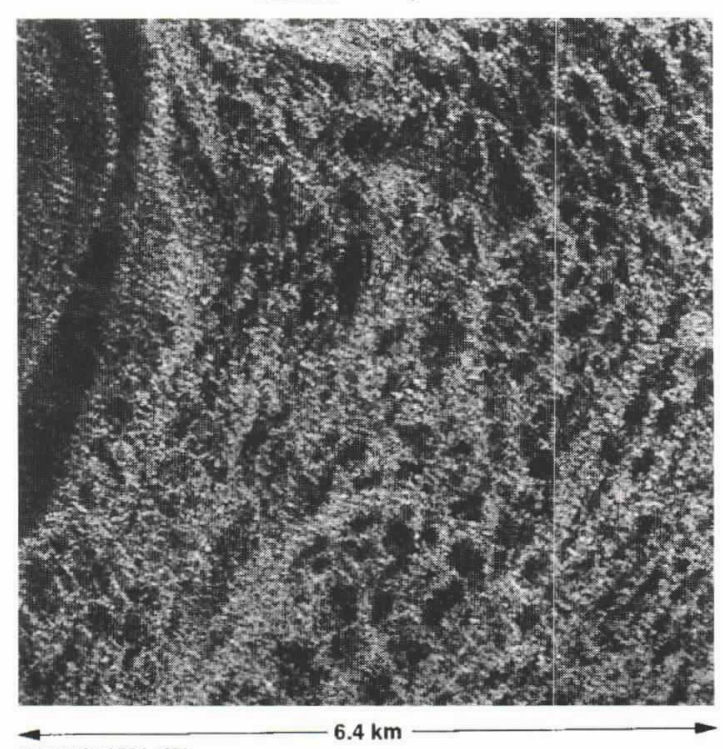

COPYRIGHT ESA 1992

(a)

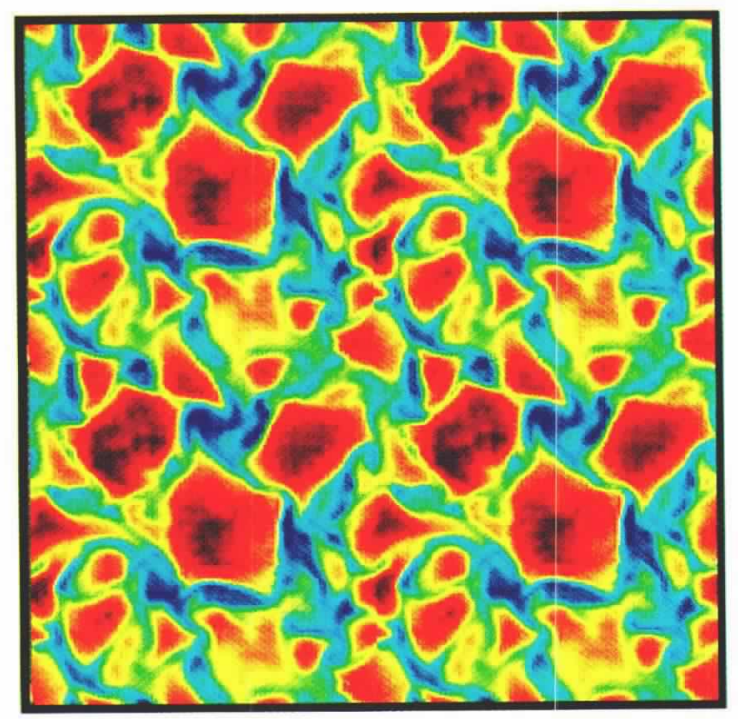

(b)

Fig. 2: (a) The surface manifestation of convection in the mixed layer is seen in the ERS-1 SAR image from the Greenland Sea. Dark areas are the open water convective return regions; white areas are ice covered. (Courtesy F. Carsey, Carsey and Garwood, 1993). (b) The LES experiment potential temperature pattern at the surface showing ocean mixed-layer convective cells; these are similar to Rayleigh-Bernard cells except that they occur under rotation and are unsteady. The spatial scales are consistent with that found in the SAR image (Carsey and Garwood, 1993).

The thermobaric effect can be manifest in two types of conditional instabilities (Garwood, 1992a). Either a parcel instability or a layer instability can episodically release potential energy that has been stored seasonally. Both of these instabilities are dependent on the likelihood that a water parcel or water column that was hydrostatically stable near the surface could become hydrostatically unstable if displaced downward with commensurate pressure increase.

A parcel instability occurs when a mixed layer parcel penetrates below a critical depth and, having become more dense than the ambient water, continues to sink, thereby escaping the well-mixed surface layer and penetrating the pycnocline. This process is analogous to the similarly named process in the atmospheric boundary layer that is associated with cumulus formation (Garwood, 1992a). Penetrative convection is when a plume overshoots the depth of static stability due to the momentum in the plume. When penetrative convection occurs, it causes additional mixing at the mixed-layer base beyond that predicted by hydrostatic adjustment. Additional penetration or super-penetration may be possible when the thermobaric instability provides additional downward momentum to the parcel.

A related layer instability may occur if the whole mixed layer is downwelled in response to large-scale convergence associated with wind forcing (Ekman pumping) or by preconditioning associated with larger-scale dynamics. Layer instability may occur for stratified layers as well as for subducted or surface-stratified layers that are no longer in immediate contact with turbulent fluxes from atmospheric forcing. This is a proposed explanation for the plumes observed by Scott and Killworth (1991) in the Iceland Sea, after the end of surface-forced winter convection.

Numerical and tank modeling experiments have illustrated the role of rotation in the process of deep convection and the morphology of convective plumes and other features (Fernando et al., 1989; Boubonov and Golitsyn, 1990; Maxworthy and Narimousa, 1994). The scaling for rotation is of interest for parameterizing the individual plume elements. Mesoscale features of convection, such as chimneys and associated eddies, are clearly dominated by the effects of rotation; individual plumes of limited vertical extent may or may not be strongly affected. Both the vertical $\left(f_{z}\right)$ and northerly $\left(f_{y}\right)$ components of rotation may influence oceanic convection. High-resolution oceanic convection modeling efforts by Denbo and Skyllingstad (1994) and Garwood et al. (1994) demonstrate the importance of retaining both the horizontal and vertical components of rotation. The energetics and flow field of individual plumes are substantially affected by the addition of the horizontal component of the Coriolis force. In the absence of rotation, vertical motions are more energetic. The diameters of plumes under the influence of rotation are smaller $(300-500 \mathrm{~m})$ in contrast to the diameters of plumes without rotation $(1,000 \mathrm{~m})$.
Penetrative convection

is when a plume

overshoots the depth

of static stability due

to the momentum in

the plume. 


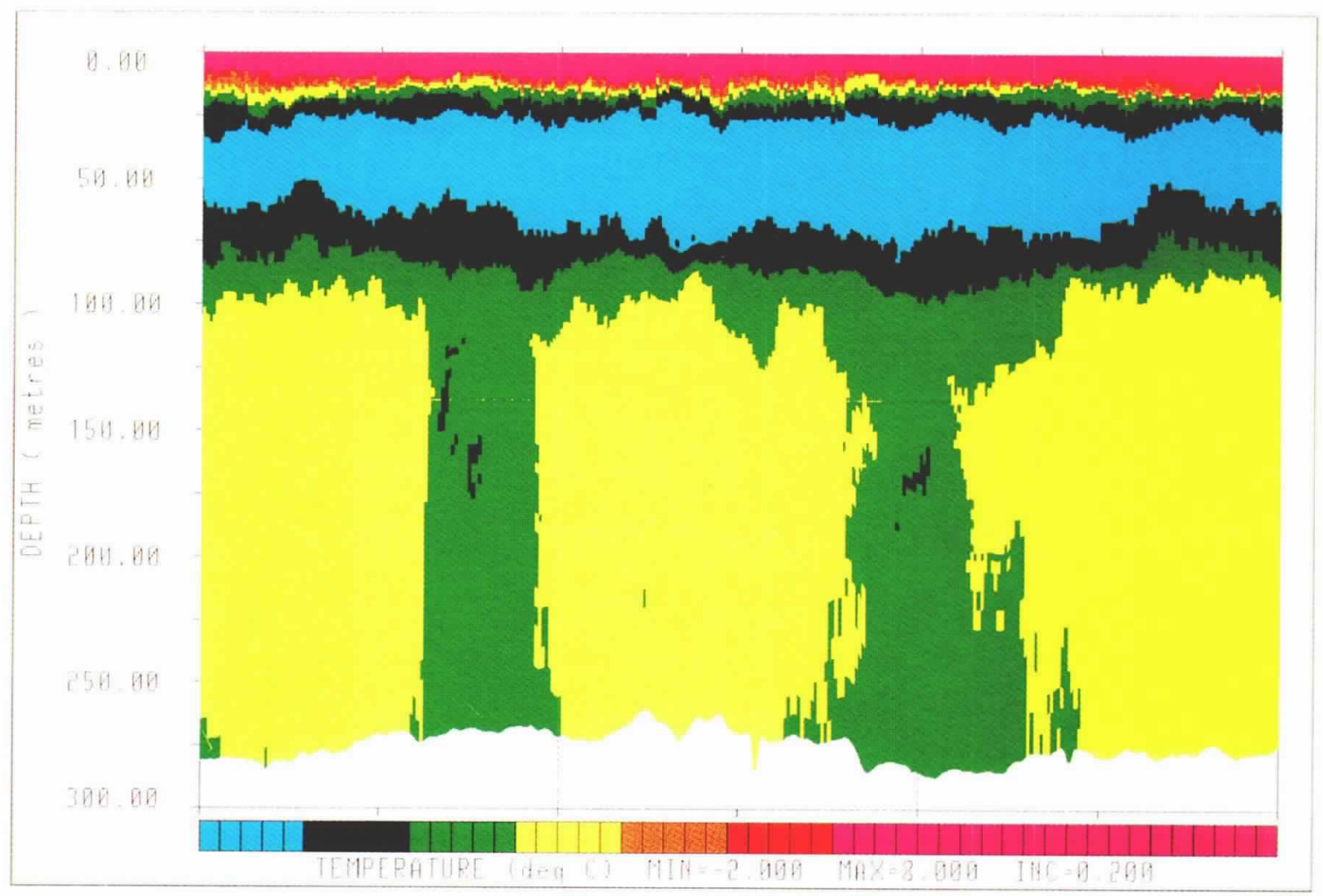

(a)

LEs models are designed to resolve the largest turbulent motions in geophysical boundary-layer problems.

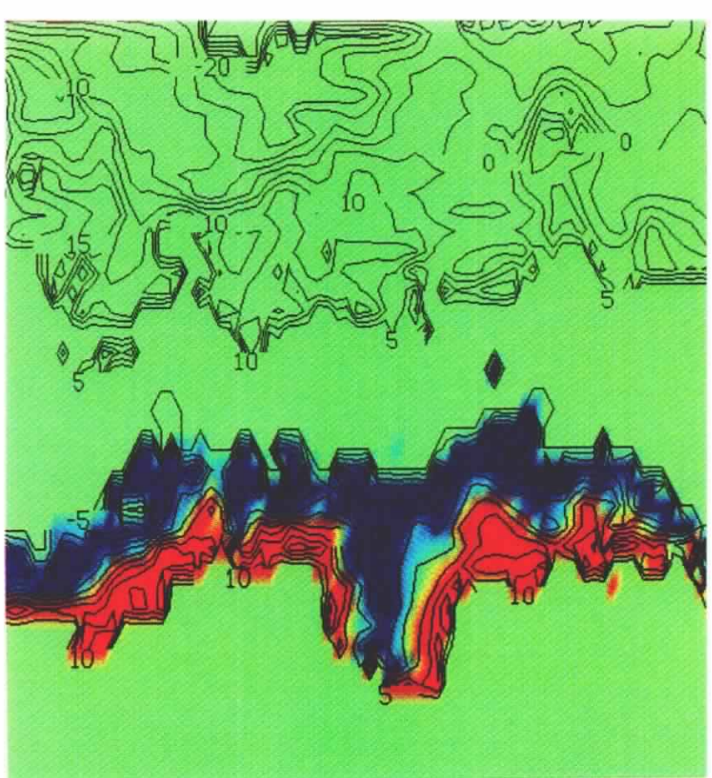

(b)

Fig. 3: (a) Thermistor chain observations of the $X-Z$ temperature structure showing two convective plumes in the Greenland-Iceland Sea (Courtesy J. Scott, Scott and Killworth, 1991). (b) The X-Z potential temperature structure from an LES experiment with super-penetration by a parcel instability initiated by surface cooling (Courtesy R. Garwood).

\section{Numerical Simulations of Deep Convective Plumes}

Recent improvements in computing power have facilitated the use of large-eddy simulations (LES) as a new tool to help oceanographers study complex geophysical flows (Galperin and Orszag,
1993; Mason, 1994). LES models are designed to resolve the largest turbulent motions in geophysical boundary-layer problems. These models typically resolve a portion of the Kolmogorov inertial subrange. Several investigators are studying deep ocean convection using ocean LES models (Denbo 
and Skyllingstad, 1994; Garwood et al., 1994) and nonhydrostatic models (Jones and Marshall, 1993). The convective plume structure, onset of instability and TKE spectrum from the LES models are complementary and in general agreement. The LES model results demonstrate the importance of thermobaricity and rotation for deep convection in the ocean.

Denbo and Skyllingstad $(1992,1994)$ used the ocean large-eddy simulation model (OLEM) for deep oceanic convection to simulate the temperature presented in Figure 4, a and b. The number of plumes decreases rapidly with depth, and the deepest plumes penetrate through regions of stably stratified water. Many plumes travel downward at an angle from the vertical because of the horizontal component of the Earth's rotation. In Figure $4 \mathrm{~b}$, an expanded section of a plume at $X^{\prime}-X$ and $Y^{\prime}-Y$ (Fig. 4a), shows the detailed structure of an individual plume. The plume has penetrated to $1400 \mathrm{~m}$ and has a horizontal scale of $300 \mathrm{~m}$, with a maximum vertical velocity of $0.05 \mathrm{~m} \mathrm{~s}^{-1}$. Turbulent velocities associated with the plume are causing fluid to be entrained into the plume and water to be mixed upward from the strong thermocline at $1200 \mathrm{~m}$.

Figure $4 c$ shows the results from the Garwood et al. (1994) LES model of thermal convection in a cold, deep $(3.6 \mathrm{~km})$, initially homogenous layer. This LES simulation confirmed the mid-depth TKE maximum for thermobaric convection. The downward acceleration due to thermobaricity may have caused the bottom of the descending plume to separate from the upper part of the plume.

The surface expression of convective plumes is illustrated in Figure 2b (Carsey and Garwood, 1993). An accompanying ERS- 1 SAR image (Fig. 2a) shows a pattern that compares in scale to the convective cells from the LES simulation. Additional LES experiments have shown the onset of super-penetration of plumes. Figure 3a shows observations from Scott and Killworth (1991) of the onset of super-penetration by a cold plume from the overlying fully turbulent mixed layer into the underlying stratified water. Figure $3 \mathrm{~b}$ shows the results of an LES experiment in which surface cooling is initiated and a parcel of mixed layer water penetrates the halocline as a parcel instability. The plume descends from an initial 200-mthick mixed layer of near-freezing water into warmer, saltier water. In spite of the difference in scales, it is plausible that the instability mechanism simulated with the LES model is similar to that responsible for the event observed by Scott and Killworth (1991).

Analysis of the LES simulations shows the integrated effects of deep convective plumes on climate-related variables, such as heat flux. For example, Figure 5 shows a measure of vertical heat flux for simulations using the full representation of rotation (5a), no rotation (5b) and nonthermobaric $(5 \mathrm{c})$ cases. The main features are as follows: 1) the onset of convection occurs earlier in the thermobaric case (vs. nonthermobaric case), 2) full plume development take less time with no rotation (vs. with rotation), and 3) vertical motions are more energetic in the case with no rotation (vs. with rotation). The nonthermobaric case does not produce penetrative plumes, and the mixed layer deepens much more gradually than it should.

\section{Parameterizations for Basin-Scale and Climate Modeling}

Ocean General Circulation Models (OGCMs) used for climate simulations use coarse resolution and integrate over long time scales; consequently, much of the physics important to mixing falls into the subgrid scale and must be parameterized. Consequently, the parameterization of vertical mixing processes, such as deep convection, is a factor in determining the distribution of heat and greenhouse gases throughout the global ocean. In fact, recent efforts in climate modeling emphasize the importance of high-latitude deep convection in both the downward transport of $\mathrm{CO}_{2}$-laden water from surface to depth (Siegenthaler and Sarmiento, 1993) and the ventilation of the deep ocean that drives the thermohaline circulation (Manabe and Stouffer, 1993). Although some OGCMs provide realistic descriptions of ocean circulation and mixing, they contain many simplifications that have uncertain effects on the up take of anthropogenic $\mathrm{CO}_{2}$ (Orr, 1993).

Most OGCMs use a convective adjustment scheme in which two vertically adjacent grid points are compared. If the top point is more dense than the one below, the temperature and salinity are mixed until they are neutrally stable with respect to each other. In reality, adjacent layers of the ocean do not mix in this way. Consequently, the models using this scheme or one with a diffusion coefficient are unable to simulate penetrative convection.

Garwood (1991) used an entrainment model that included the nonlinearities of the equation of state in order to evaluate the effectiveness of a one-dimensional mixed-layer model for simulating deep convection. He found that the wind stressgenerated turbulence and vertical turbulence enhanced vertical flux rates, and entrainment mixing substantially increased vertical convection.

A complementary approach to the parameterization of deep convection is to adapt a plume model to capture the essential physics of the vertical mixing associated with unresolved convective plumes. Parameterization schemes for deep convective activity in the atmosphere have been used in the meteorological community for many years (e.g., Kuo, 1974; Fritsch and Chappell, 1980). The argument for the use of atmospheric convection parameterizations is also applicable to the oceanic 


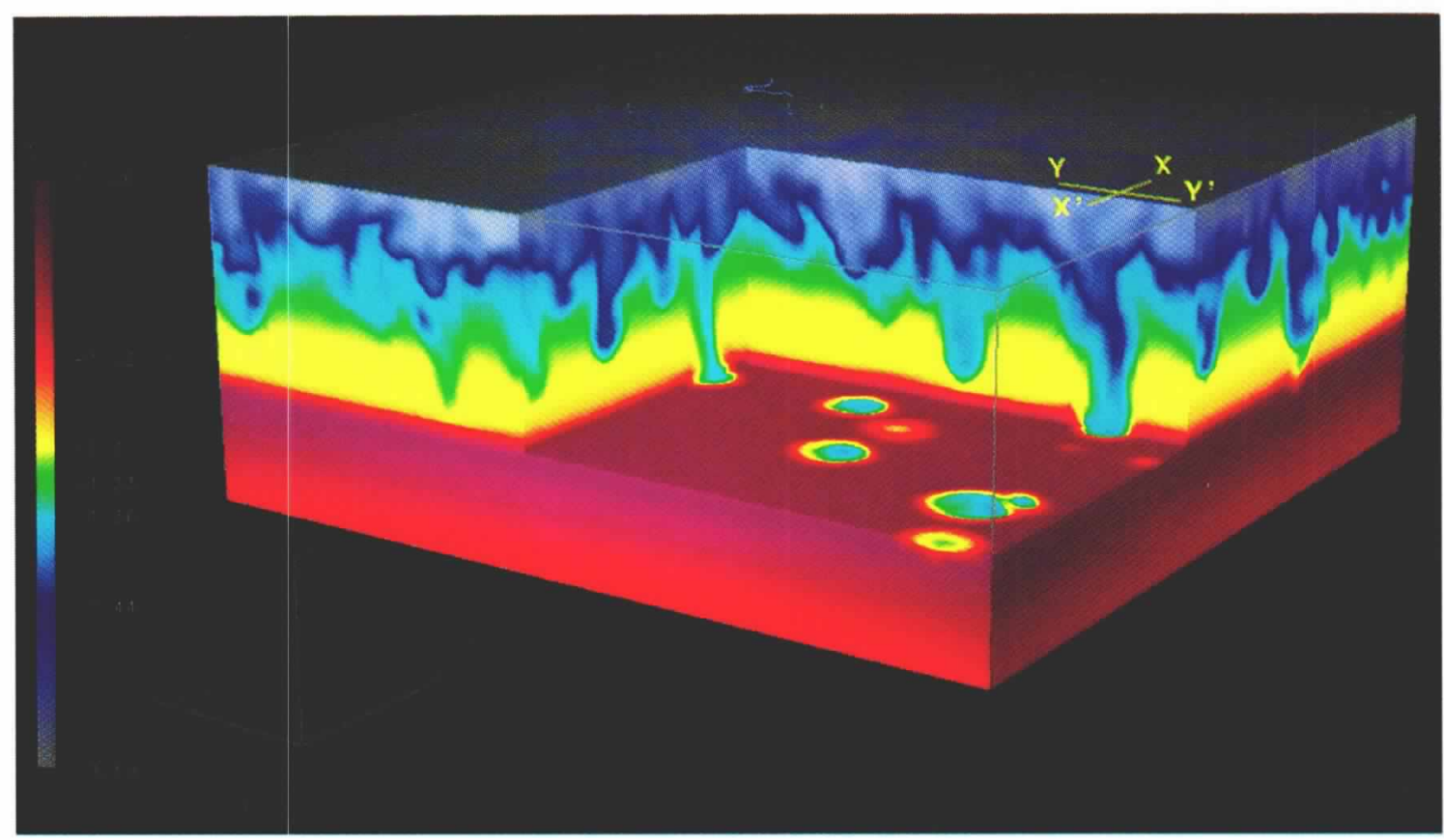

(a)

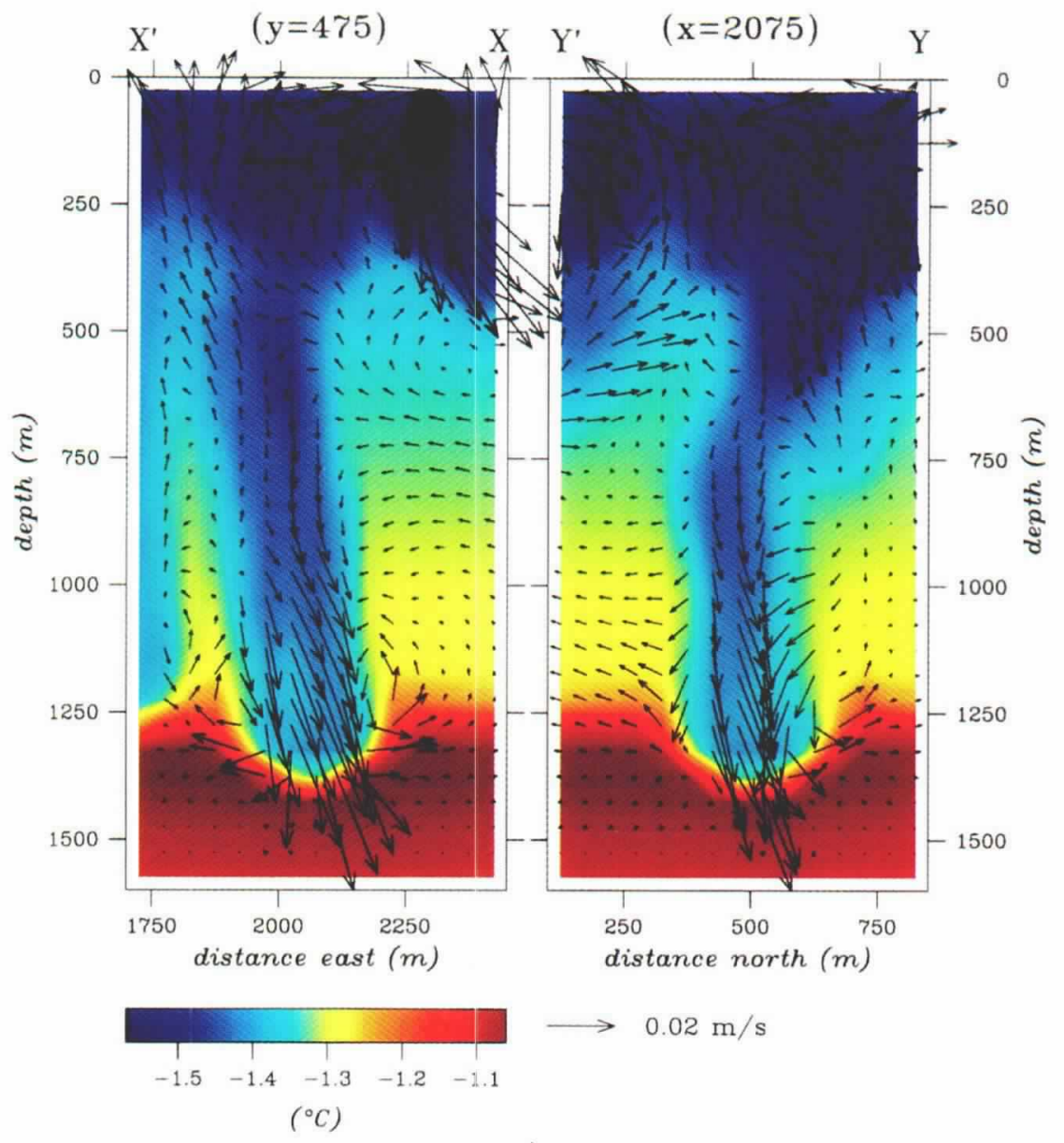

(b)

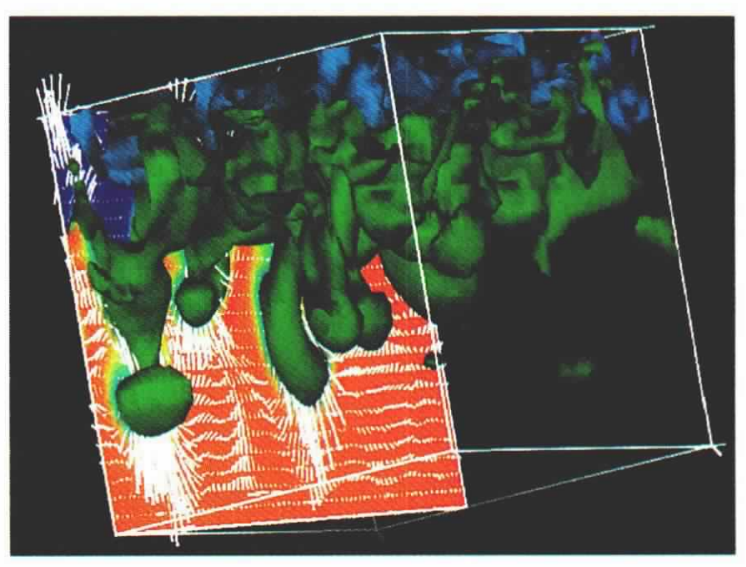

(c)

Fig. 4: (a) Three-dimensional cutaway view of potential temperature from an LES experiment using a wintertime Greenland Sea temperature-salinity profile and full rotation. The lines $X-X^{\prime}$ and $Y-Y^{\prime}$ indicate the location and orientation of potential temperature-velocity sections. The temperature scale has been adjusted to improve visualization

of the super-penetrative plumes. Each leg of the triad axis is 1,000 $\mathrm{m}$ long. The top 2,000 $\mathrm{m}$ of the domain is displayed and the origin is located at the lower, front corner. (Courtesy D. Denbo). (b) The detailed structure of an individual convective plume taken at location $X-X$ and $Y-Y$ as viewed from the $X$ and $Y$ perspective. (c) The three-dimensional view of potential temperature surfaces from an LES experiment that shows plumes breaking away. The blue isothermal surface is $-1.806^{\circ} \mathrm{C}$, and the green isothermal surface is $-1.802^{\circ} \mathrm{C}$, the domain is $3.6 \mathrm{~km}^{3}$. The LES temperature field is initially uniform and plume formation is forced by cooling at the surface (Garwood et al., 1994) 
case. Because the horizontal scale of cumulus clouds (or deep convective plumes in the oceanic case) is much smaller than the grid scale used to represent mesoscale flows, the influence of the small-scale convective motions must be represented parameterically.

Paluszkiewicz et al. (1994) and Paluszkiewicz and Romea (1994) developed a plume-based deep convection parameterization, and in this scheme, the vertical column of values for potential temperature and salinity are handed to the plume model by the OGCM. A measure of the available buoyant energy defines the vertical stability of a fluid column and controls the amount of plume activity in the grid column. The plume parameterization is based on an entrainment hypothesis, which is used to estimate the depth-dependent mixing with the environment. Compensating upward motion in the environment follows from mass continuity affecting the vertical structures of environmental temperature and salinity. The grid-point variables are reconstructed as area-weighted means of plume and environment values. In practice, this scheme replaces any convective adjustment scheme used and can be inserted in the same place in the OGCM code (Paluszkiewicz and Romea, 1994). A plume model using similar physics but a different implementation was developed by Alves (1993).

\section{Concluding Remarks About Future \\ Observational and Modeling Work}

Large-eddy simulations have been shown to be a useful tool in establishing scales and exploring the governing physics of convective plumes. Continued explorations with these and other models, together with additional and new forms of observations of deep convection, are needed to understand the process more fully. In situ ADCPs and other moored observations must be supplemented by observations from instruments that can sample larger areas more rapidly. Profiling drifters, autonomous underwater vehicles and submarines that can sample the field of plumes in the wintertime Greenland or Labrador Sea would provide the statistical data to understand convective plumes better. LES experiments will be very useful in understanding this diverse set of Eulerian and Lagrangian observations. These data, together with model simulations, can be used to evaluate new parameterizations and representations of the convective process.

Several agencies are sponsoring the modeling and observational studies needed to improve our understanding and representation of deep convection. The Department of Energy $\mathrm{CO}_{2}$ Ocean Program, and Computational Hardware, Advanced Mathematics and Model Physics (CHAMMP) program sponsor research to improve the representation of key climate processes, such as deep convection, in models used to study the global circulation. The Office of Naval Research (ONR) will fund an Accelerated Research Initiative on
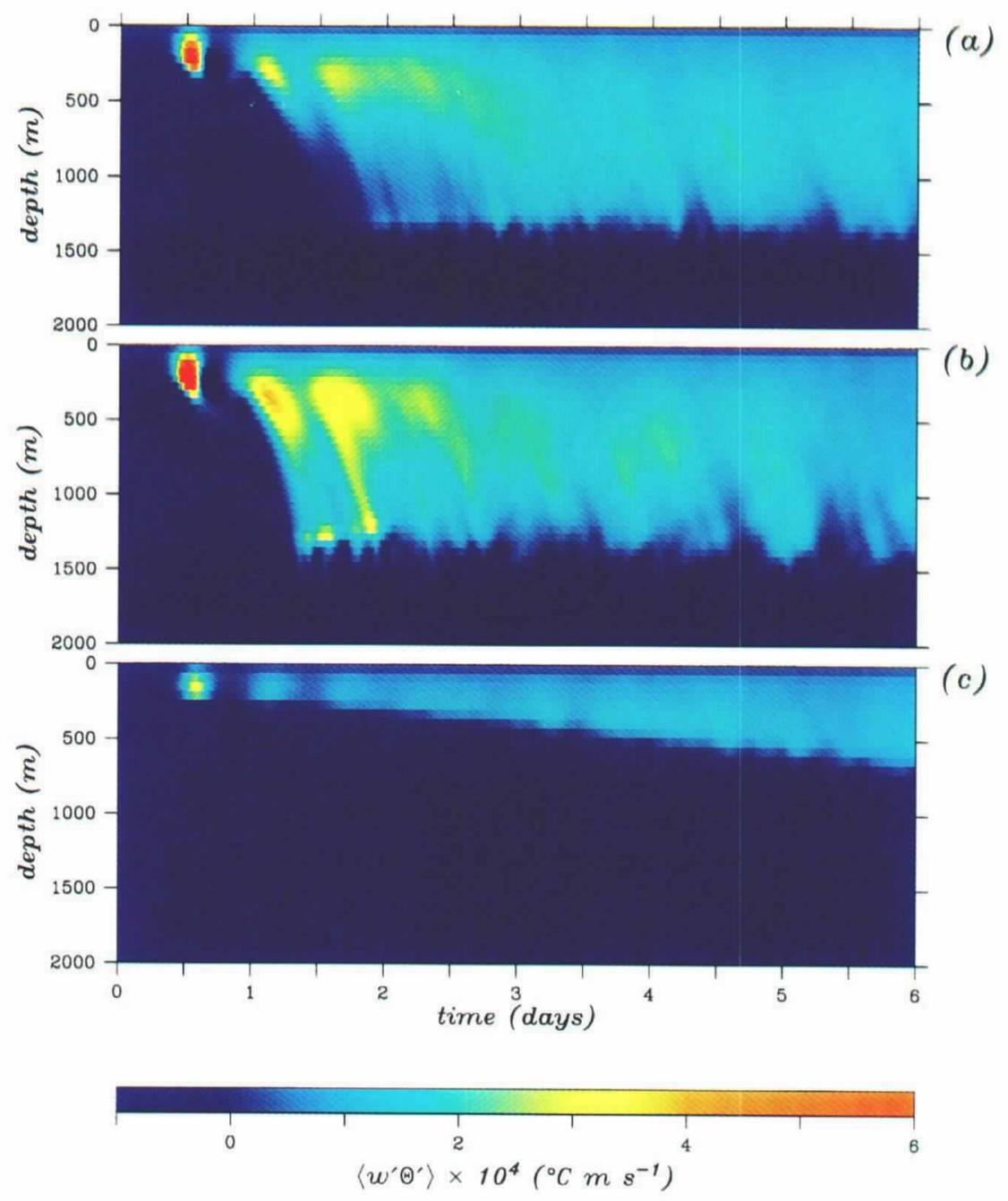

Fig. 5: Horizontal average of the temperature-vertical velocity covariance as a function of depth and time for the Greenland Sea experiments: (a) full rotation case, (b) no rotation case, and (c) nonthermobaric case. Results were multiplied by $10^{4}$ for display purposes. The domain is a $100 \times 100 \times 72$ grid of 50-m boxes. The experiment tested (a) the full equation of state and Coriolis force, (b) the full equation of state without rotation and (c) a quadratic approximation to the equation of state, without thermobaric effects, but including full rotation. In these experiments, the initial conditions were based on a CTD profile taken in the central Greenland Sea in February, 1988, and the model was forced with $-300 \mathrm{~W} \mathrm{~m}^{-2}$ of cooling and $-100 \mathrm{~W} \mathrm{~m}^{-2}$ of latent heat flux (Denbo and Skyllingstad, 1994).

Oceanic Deep Convection (D'Asaro, 1994). The World Ocean Circulation Experiment-Numerical Experimentation Group continues to emphasize the need for global ocean models to include schemes for parameterizing the smaller-scale oceanic processes, including deep convection and the mixing that occurs in overflows.

\section{Acknowledgements}

The LES studies by R. Garwood were sponsored by the National Science Foundation (DPP91-14161) and the Office of Naval Research. The work by T. Paluszkiewicz and D. W. Denbo was supported at Pacific Northwest Laboratory by the U.S. Department of Energy (DOE). Pacific Northwest Laboratory is operated for the DOE by 
Battelle Memorial Institute under contract DEAC06-76RL0 1830. We thank Frank Carsey and John Scott for permission to use their figures and A. Guest, J. Downing, and E. Skyllingstad for valuable discussions.

\section{References}

Aagaard, K. and E.C. Carmack, 1989: The role of sea ice and other fresh water in the Arctic circulation. J. Geophys. Res., 94, 14485-14498.

Alves, J.O.S., 1993: Parameterization of open-ocean deep convection, Part 1: Theoretical description of a plume ensemble model. Forcasting Res. Div. Tech. Rept. No. 49. Meteorological Office, United Kingdom, $14 \mathrm{pp}$.

Boubonov, B.M. and G.S. Golitsyn, 1990: Temperature and velocity field regimes of convective motions in a rotating plane fluid layer. J. Fluid. Mech., 219, 215-239.

Carmack, E.C., 1990: Large-scale physical oceanography of polar oceans. In: Polar Oceanography, Part A, Physical Science. W.O. Smith, Jr., ed., Academic Press, San Diego, CA, 171-222.

Carsey, F. and R.W. Garwood, Jr., 1993: Identification of modeled ocean plumes in Greenland gyre ERS-1 SAR data. Geophys. Res. Lett., 20, 2207-2210.

D'Asaro, E., 1994: Measuring Deep Convection. Office of Naval Research Workshop Report.

Denbo, D.W. and E.D. Skyllingstad, 1992: Rotational effects on oceanic convection using a three-dimensional nonhydrostatic model. EOS, Trans. Amer. Geophys. Union., 73, 292.

and E.D. Skyllingstad, 1994: An ocean large eddy model with application to convection in the Greenland Sea. J. Phys. Oceanogr. (Submitted).

Fernando, H.J.S., D.L. Boyer and R. Chen, 1989: Turbulent thermal convection in rotating and stratified fluids. Dyn. Atmos. Oc., 1, 513-547.

Fritsch, J.M. and C.F. Chappell, 1980: Numerical prediction of convectively driven mesoscale pressure systems. 1 Convective parameterization. J. Atmos. Sci., 37, 17221733.

Galperin, B. and S.A. Orzag, 1993: Large Eddy Simulation of Complex Engineering and Geophysical Flows. Cambridge University Press, Cambridge, $600 \mathrm{pp}$.

Garwood, R.W., Jr., 1991: Enhancements to deep turbulent entrainment. In: Deep Convection and Deep Water Formation in the Oceans. P.C. Chu and J.C. Gascard, eds., Elsevier Oceanogr. Sers., New York, 197-213.

, 1992: Missing physics for deep convection? Arctic System Science Ocean-Atmosphere-Ice Interactions Modeling Workshop, Pacific Grove, Report No. I, 49-54.

S.M. Isakari and P.C. Gallacher, 1994: Thermobaric convection. In: The Role of the Polar Ocean in Shaping the Global Environment. O. Johannessen, R. Muench and $\mathbf{J}$. Overland, eds., AGU Monograph.

Gascard, J.C., 1991: Open ocean convection and deep water formation revisited in the Mediterranean, Labrador, Greenland and Weddell Seas. In: Deep Convection and Deep Water Formation in the Oceans. P. Chu and J. Gascard, eds., Elsevier, Oceanogr. Ser., 157-181.

and R.A. Clarke, 1983: The formation of Labrador Sea water. II. Mesoscale and smaller-scale processes. $J$. Phys. Oceanogr., 13, 1779-1797.

Gill, A.E., 1973: Circulation and bottom water formation in the Weddell Sea, Deep-Sea Res., 20, 111-140.

Guest, P.S. and K.L. Davidson, 1991: Meteorological triggers for deep convection in the Greenland Sea. In: Deep Convection and Deep Water Formation in the Oceans.
P. Chu and J. Gascard, eds., Elsevier, Oceanogr. Ser., 369-375.

Jones, H. and J. Marshall, 1993: Convection with rotation in a neutral ocean: A study of open-ocean deep convection. J. Phys. Oceanogr, 23, 1009-1039.

Killworth, P.D., 1979: On chimney formations in the ocean. $J$. Phys. Oceanogr., 9, 531-554.

1983: Deep convection in the world ocean. Rev. Geophys. Space Phys., 21, 1-26.

Kuo, H.L., 1974: Further studies of the parameterization of the influence of cumulus convection on large-scale flow. $J$. Atmos. Sci., 31, 1232-1240.

Manabe, S. and R.J. Stouffer, 1993: Century-scale effects of increased atmospheric $\mathrm{CO}_{2}$ on the ocean-atmosphere system. Nature 36, 215-218.

Mason, P.J., 1994: Large-eddy simulation: A critical review of the technique. Q.J.R. Meteorol. Soc., 120, 1-26.

Maxworthy, T. and S. Narmousa, 1994: Unsteady deep convection in a homogenous rotating fluid. J. Phys. Oceanogr., $24,865-887$.

McDougall, T.J., 1984: The relative roles of diapycnal and isopycnal mixing on subsurface watermass conversion. J. Phys. Oceanogr., 14, 1577-1589.

1987: Thermobaricity, cabbeling, and water-mass conversion, J. Geophys. Res., 92, 5448-5464.

Orr, J.C., 1993: Accord between ocean models predicting uptake of anthropogenic $\mathrm{CO}_{2}$. Water, Air, and Soil Pollution, 70, 465-481.

Paluszkiewicz, T., L.F. Hibler, R. Romea and E.D. Skyllingstad, 1994: Greenland Sea deep convection: results from an OGCM with a new convective parameterization. EOS, Trans. Amer. Geophys. Union., 75, 189.

and R. Romea, 1994: A one-dimensional model for the parameterization of deep-convection in the ocean. Dyn. Atms Oceans (submitted).

Roach, A.T., K. Aagaard and F. Carsey, 1993: Coupled iceocean variability in the Greenland Sea. AtmosphereOcean, 31, 319-337.

Rudels, B., D. Quadfasel, H. Friedrich and M.-N. Houssais, 1989: Greenland Sea convection in the winter of 1987 1988. J. Geophys. Res., 94, 3223-3227.

Sankey, T., 1973: The formation of deep water in the northwestern Mediterranean. Prog. Oceanog., 5, 159-179.

Schott, F. and K.D. Leaman, 1991: Observations with moored acoustic doppler current profilers in the convective regime in the Golfe du Lion. J. Phys. Oceanogr., 21, 558-574.

, M. Visbeck and U. Send, 1993a: Open ocean deep convection, Mediterranean and Greenland Seas In: Ocean Processes in Climate Dynamics. P. MalanotteRizzoli and A. Robinson, eds., Kluwer, New York, 203-225.

M. Visbeck and J. Fischer, 1993b: Observations of vertical currents and convection in the Central Greenland Sea during the winter of 1988-1989. J. Geophys. Res., 98, 14402-14421.

Scott, J.C. and P.D. Killworth, 1991: Upper ocean structures in the south-western Iceland Sea: a preliminary report. In: Deep Convection and Deep Water Formation in the Oceans. P. Chu and J. Gascard, eds., Elsevier, Oceanogr. Ser., 107-121.

Siegenthaler, U. and J.L. Sarmiento, 1993: Atmospheric carbon dioxide and the ocean. Nature, 365, 119-125.

Solomon, H., 1974: Comments on the arctic bottom water problem and high-latitude thermohaline sinking. J. Geophys. Res., 7, 881-884

The THETIS Group, 1994: Open-ocean deep convection explored in the Mediterranean. EOS, Trans. Amer. Geophys. Union., 75, 217-220. 